\title{
Is Money an Omitted Variable in the Production Function? Some Further Results
}

\author{
M. AYNUl HASAN ${ }^{1}$ \\ Associate Professor, Department of Economics, Acadia University, Wolfville, \\ Nova Scotia, BOP 1X0, Canada,
}

SYED F. MAHMUD

Associate Professor, Department of Economics, Bilkent University, Ankara, Turkey

Abstract: In recent years, numerous studies have emphasized the role of real balances in the production function in terms of money being useful: as an intermediate good; as liquid reserves for investment; and also serving as a link between aggregate supply and the nominal interest rate. In this paper we report new Canadian empirical evidence regarding the important role of money in the production process of aggregate manufacturing industries based on a flexible translog cost function approach. In general, our results support the hypothesis that money is an important factor in the production function and that there are potential supply side effects of a change in the interest rate.

JEL Classification System-Number: E41

\section{Introduction}

Over the past two decades a number of papers have appeared in the literature to examine the importance of real balances in the production function. The theoretical basis for incorporating real balances in the production function is based on the premise that money is held not for its own sake but as an intermediate good for the services it can provide. ${ }^{2}$ Friedman (1969) has also

\footnotetext{
1 We wish to thank L. Paquin, E. Ghysels, A. Abouchar, C. Christ, M. Khan and, in particular, an anonymous referee for detailed helpful comments. An earlier version of the paper was presented at the Annual meeting of the Canadian Economics Association, Windsor, Ontario, 1988. A part of the paper was revised while the first author was visiting the Johns Hopkins University - he would like to thank the members of the Department of Economics for their hospitality. This project was funded by the Harvey T. Reid Summer Fellowship and the SSHRCC General Grant at Acadia University.

2 Indeed money is also held for a variety of other reasons e.g., transaction demand, strategic liquid reserve for investment, speculative money to build up financial assets. (This was pointed out by the referee.)
} 
argued that money should be treated as a productive input analogous to capital or labour in explaining the behaviour of the firm. On the other hand, Harkness (1984) and Jansen (1985) argued that real balances provide a link between real output and the nominal interest rate on the aggregate supply side of the economy. ${ }^{3}$ In the literature, however, not much has been explored regarding the macroeconomic supply-side effects of the real money balances via the production function approach. In a similar context, Dennis and Smith (1978) have argued that motives for holding money balances by individual households may be quite different from that of the firms and, therefore, the use of a single equation to represent the demand for money for both these groups in the macroeconomic models would be "too much of a compromise of economic theory".

In the context of the Canadian economy, there are some studies that have investigated empirically the role of real money balances in the aggregate production function [e.g., You (1981), Sephton (1986) and others]. These studies seem to provide strong evidence for the hypothesis that real money balances do belong in the aggregate production function. The purpose of this paper is to report some new empirical evidence on the role of real balances as a productive factor for the aggregate Canadian manufacturing industries over the period 1965-87 using a more flexible translog cost function approach. We use Zellner's seemingly unrelated estimation technique to estimate the cost and the factor share equations (capital, non-production worker, production labour and real money balances). Our results, in general, confirm that the real money balance is an important determinant in the production technology of the Canadian aggregate manufacturing industries.

Section 2 explains the derivation of the translog cost function, the associated factor share equations and various elasticities. Section 3 reports the regression results and elasticity estimates while Section 4 presents a summary and concluding remarks. Appendix $A$ provides the definition and derivation of user cost of capital relevant to the Canadian manufacturing sector. Appen$\operatorname{dix} B$, on the other hand, presents the discussion on the estimation procedure.

3 Jansen (1985), referring to Lucas and Rapping (1969), argued that the presence of real balance in the aggregate supply function captures the effect of wealth on supply. If there is a statistical justification for the above argument, then, through the real balance, interest rate will appear in the demand function for labour. Consequently, a change in the interest rate may not only have an impact on the aggregate demand side (via money demand function) but now it may also have an influence on the aggregate supply (via labour demand). 


\section{A Translog Cost Minimization Model}

In order to empirically estimate the underlying factor demand function for real balances and other inputs of a firm, one can follow either the production function or the associated cost function approach. The application of duality theory to this optimization problem stipulates that, under some regularity conditions [e.g., see Caves and Christensen (1980)], there is a unique correspondence between the production function and the cost function. Furthermore, all the information about the underlying technology is also contained in each of these functions [Shepard (1970)].

Suppose a firm uses inputs capital $\left(X_{k}\right)$, production worker $\left(X_{u}\right)$, nonproduction worker $\left(X_{s}\right)$ and real money balances $\left(X_{m}\right)$ to produce output $Q$. The production function can then be written as

$$
Q=F\left(X_{k}, X_{s}, X_{u}, X_{m}\right)
$$

Assuming that Equation (1) is concave, twice differential and that firm minimizes cost, then there exists a cost function that is dual to Equation (1) and relates cost to the output level and factor prices:

$$
C=G\left(Q, P_{k}, P_{s}, P_{u}, P_{m}\right),
$$

where $C$ is the total nominal cost, $Q$ is the real output and $P_{i}$ s are the factor prices of capital, skilled labour, unskilled labour and real balances.

In this study, we employ the translog cost specification to estimate our empirical model. This specification can be viewed as a second-order logarithmic approximation to an arbitrary twice-differential production function [Christensen, Jorgenson and Lau (1973)]. A translog cost function (locally) imposes no a priori restrictions on the substitution possibilities among the factors of production. This is especially desirable in our study where we would like to allow the elasticities of substitution between money and other inputs to be able to assume any value. The translog cost function can be written as:

$$
\begin{aligned}
\ln (C)= & \alpha_{0}+\alpha_{q} \ln Q+(1 / 2) \gamma_{q q}(\ln Q)^{2}+\sum_{i} \alpha_{i} \ln P_{i} \\
& +(1 / 2) \sum_{i} \sum_{j} \gamma_{i j}\left(\ln P_{i}\right) \cdot\left(\ln P_{j}\right)+\sum_{i} \gamma_{q i}(\ln Q)\left(\ln P_{i}\right),
\end{aligned}
$$

$i, j=k, s, u, m$.

In order to correspond to a firm's budget constraint, the above cost function must be homogeneous of degree one in factor prices. This imposes the following adding up restrictions on the cost function: 


$$
\sum_{i} \alpha_{i}=1 ; \quad \sum_{i} \gamma_{q i}=0 ; \quad \sum_{i} \gamma_{i j}=\sum_{j} \gamma_{i j}=\sum_{i} \sum_{j} \gamma_{i j}=0
$$

In addition to the adding up restrictions, symmetry on the $\gamma_{i j}$ matrix is also imposed. The factor demand equations are derived by partially differentiating the cost function with respect to the factor prices and applying Shephard's lemma: $\partial C / \partial P_{i}=X_{i}$; where $i=k, s, u, m$. This result may be conveniently expressed in logarithmic form in the case of the translog function:

$$
\partial \ln C / \partial \ln P_{i}=\partial C / \partial P_{i} \cdot P_{i} / C=X_{i} \cdot P_{i} / C=S_{i}
$$

where $S_{i}$ indicates the cost share of the $i$ th factor input. The translog cost function represented by Equation (3) yields the following share equation:

$$
S_{i}=\alpha_{i}+\gamma_{q i} \ln Q+\sum_{i} \gamma_{i j} \ln P_{i}, \quad \text { where } \quad i, j=k, s, u, m
$$

The cost equation (3) and the four share equations (capital, two kinds of labourers and real money balances) of the form of Equation (6) constitute our model.

\section{Factor Demand Elasticities}

Uzawa (1962) has shown that Allen's partial elasticities of substitution for the translog cost function can be computed directly from the cost function equation (3) by the formula. ${ }^{4}$

$$
\sigma_{r k}=C \cdot C_{r k} / C_{r} C_{k}
$$

where subscripts indicate partial differentiation with respect to factor prices. For the translog cost function specified by Equation (3), Allen's substitution elasticities can be calculated as:

$$
\begin{aligned}
& \sigma_{r k}=\left(\gamma_{r k}+S_{r} S_{k}\right) / S_{r} S_{k}, \\
& \sigma_{r r}=\left\{\gamma_{r r}+S_{r}\left(S_{r}-1\right)\right\} / S_{r}^{2} .
\end{aligned}
$$

The own price elasticities of factor demand $\left(\xi_{i i}\right)$ can be obtained from

\footnotetext{
4 For a detailed derivation of own and cross price elasticities, see Binswanger (1974).
} 


$$
\xi_{r r}=\sigma_{r r} S_{r}
$$

and, similarly, the cross price elasticities of factor demand can be written as:

$$
\xi_{r k}=\sigma_{r k} S_{r}
$$

where $\xi_{r k}$ is interpreted as the percentage change in the demand for the $r$ th factor as a result of a one percent change in the price of factor $k$.

\section{Data and Estimation Procedure}

Data: We estimate the parameters of the cost function in Equation (3) for four factors, namely, capital, production labour, non-production worker and real money balances using annual data on aggregate Canadian manufacturing industries over the period 1965-87.

The data on real output, $Q$, was derived by deflating current dollar gross domestic product of the total manufacturing sector by its price index. ${ }^{5}$ Two different kinds of labour inputs were considered, i.e., production and related workers $\left(X_{u}\right)$ and administrative, office and other non-manufacturing employees $\left(X_{s}\right)$ and they are measured as the total man-hours worked by the employee. Since Statistics Canada (STC) reports only the number of bodies for non-production workers, following Smith and Dennis (1978), we multiplied the total number of bodies by $37.5 \times 52$ to obtain annual hours worked by the non-production employees. The wage rates $\left(P_{u}\right.$ and $\left.P_{s}\right)$ have been derived by dividing total wages and salaries paid to each type of worker by their respective total man-hours.

The data for the real money balances $\left(X_{m}\right)$ has been obtained from the year-end balance sheet of the total manufacturing sector. Cash and marketable securities have been taken as the measure of nominal money balances. The data for real balances was subsequently derived by dividing nominal money by industry selling price index of the total manufacturing sector. The price of holding one nominal dollar is measured by the interest rate (r). In our model, we assume that the services derived from the nominal

5 We are aware of the fact that, under a perfectly competitive equilibrium (zero-profit condition), the output price only covers the unit cost of production which, in the context of dual, would amount to $C=Q$. This implies that the gross value of $Q$ must include all costs including the cost of real balances. Since, in this study, we are not making a perfectly competitive market assumption (zero-profit condition), the equality of $Q=C$, is, therefore, not a binding constraint for our analysis. (We are thankful to the referee for making this point.) 
money to the firms are directly proportional to the levels of real stocks of money. The price of holding one real dollar $\left(P_{m}\right)$ is the interest rate multiplied by the price level. Thus, an increase in the price level will increase the price level of money services.

The data on real capital stock is measured as the mid-year real net capital stock times the capacity utilization rate of the total manufacturing sector. The price of capital stock $\left(P_{k}\right)$ is the user cost of capital and its methodology has been adopted from Lodh (1984). In the construction of the user cost series, Lodh (1984) has employed a discount rate which is inflation free and is a weighted average of real industrial bond rate and real equity. It is important to note that in the construction of the user cost of capital Lodh (1984) has used the notion of adaptive expectations to form the expectations about the effective corporate tax rate and the inflation rate. However, in our empirical model which deals with production decisions of the firms, ignoring the financial portfolio decisions of the firms, we assumed static expectations about all the factor prices and output cost. Given the definitions of all input factors and their respective prices, the total cost $(C)$ is then simply the sum of the total nominal values of these factor inputs. (Appendix A outlines the construction of the user cost of capital.)

Estimation Procedures: The parameters of the tranlog cost function can be estimated in one of three ways. First, one can use ordinary least squares to estimate the cost function only. This technique is attractive from the point of view of simplicity. However, it neglects the additional information contained in the cost share equations [Christensen and Greene (1976)]. Secondly, we can estimate the set of share equations in a simultaneous equation framework, excluding the cost equation. For instance, Berndt and Wood (1975) have estimated share equations as a multivariate regression system. Finally, Christensen and Greene (1976) have estimated the cost function together with the share equations. We follow this last approach to estimate the parameters of the cost and share equations. (See Appendix B for a discussion on the estimation procedure used in the study.)

\section{Discussion of Results}

The translog cost function and the three share equations (as presented in Appendix B) for the aggregate Canadian manufacturing industries ${ }^{6}$ were esti-

6 We have also estimated the cost and share equations and the corresponding different types of elasticities for the disaggregated 2 digit manufacturing industries. These results are available on request from the authors. 
mated using Zellner's seemingly unrelated algorithm in the TSP computer programme. Four versions of the model were estimated by dropping one share equation each time. This enables us to check on the invariance of the estimated parameters with respect to the share equation dropped. We did observe this invariance property and in Table 1, we, however, report only the parameter estimates of the share equations dropping capital. In most cases the estimated parameters are significantly different from zero at the ninety-five percent level of confidence.

The estimated own, cross and substitution price elasticities are all significant at the one percent level and they are presented in Table 2. As expected, the own price elasticities of demand for the factors were negative. With the exception of non-production workers $\left(X_{s}\right)$, the own price elasticities of demand for all other factors including real balances seem to be fairly inelastic. It is interesting to note that the own price elasticity of real money balances for the Canadian manufacturing industries is close to the estimates of Dennis and Smith's (1978) study based on the US manufacturing sector data. Their estimates of the price elasticity of money ranged between -0.22 to -0.40 .

Table 1. Translog parameter estimates of the share equations (dropping capital)

\begin{tabular}{lrr}
\hline Parameters & Estimates & $t$-values \\
\hline$\alpha_{0}$ & -24.883 & -3.894 \\
$\alpha_{q}$ & 6.332 & 1.349 \\
$\alpha_{q q}$ & -0.571 & -3.931 \\
$\alpha_{s}$ & 0.790 & 5.960 \\
$\alpha_{u}$ & 0.306 & 0.820 \\
$\alpha_{m}$ & -0.012 & -2.072 \\
$\alpha_{k}$ & -0.083 & -0.191 \\
$\gamma_{s s}$ & -0.052 & -1.711 \\
$\gamma_{u u}$ & -0.025 & -1.321 \\
$\gamma_{m m}$ & 0.002 & 9.462 \\
$\gamma_{s u}$ & 0.066 & 2.559 \\
$\gamma_{s m}$ & 0.006 & 3.136 \\
$\gamma_{u m}$ & -0.009 & -4.852 \\
$\gamma_{q s}$ & -0.062 & -3.695 \\
$\gamma_{q u}$ & -0.0008 & -0.017 \\
$\gamma_{q m}$ & 0.002 & 3.154 \\
$\gamma_{k k}$ & 0.514 & 1.312 \\
$\gamma_{s k}$ & -0.021 & -1.594 \\
$\gamma_{u k}$ & -0.032 & -0.950 \\
$\gamma_{k m}$ & 0.001 & 2.200 \\
$\gamma_{q k}$ & 0.060 & 1.123 \\
Log Likelihood Value & 374.203 & \\
\hline & &
\end{tabular}


The signs of the cross price elasticities of capital with respect to (w.r.t.) money $\left(\xi_{k m}\right)$ and non-production workers w.r.t. money $\left(\xi_{s m}\right)$ are positive whereas the elasticity for the production workers $\left(\xi_{1}\right)$ is negative. This indicates that capital and non-production workers are substitutes to money whereas production workers are complementary to money. Dennis and Smith (1978) have estimated these elasticities for the US manufacturing sector and they also found the price elasticity between production worker and money to be complements (in nine out of eleven industries) whereas money and capital to be substitutes.

The elasticities of substitution $\left(\sigma_{i j}\right)$ are calculated using Equation (8) and they are also reported at the bottom of Table 2 . These substitution elasticity values between capital and production workers $\left(\sigma_{u k}\right)$ and capital and nonproduction workers $\left(\sigma_{s k}\right)$ are both less than one indicating that the substitution possibilities are very limited among these factors of production. On the other hand, the factors, production and non-production workers, seem quite substitutable with each other (e.g., $\sigma_{s u}=1.78$ ). Furthermore, when these substitution elasticity figures were calculated for each year, as presented in Table 3, they were fairly stable during the entire sample period $(1965-87)$.

Table 2. Factor price elasticities

\begin{tabular}{lrr}
\hline Parameters & Estimates & t-values \\
\hline Own & & \\
$\xi_{s s}$ & -1.080 & -6.815 \\
$\xi_{u u}$ & -0.617 & -14.207 \\
$\xi_{m m}$ & -0.395 & -6.021 \\
$\xi_{k k}$ & -0.494 & -4.567 \\
Cross Price & & \\
$\xi_{s m}$ & & 3.369 \\
$\xi_{u m}$ & 2.514 & -4.182 \\
$\xi_{s k}$ & -2.902 & 3.807 \\
$\xi_{u k}$ & 0.136 & 3.785 \\
$\xi_{k m}$ & 0.352 & 4.077 \\
$\xi_{s u}$ & 0.006 & 5.780 \\
Substitution Elasticities & 0.343 & \\
$\sigma_{s m}$ & & 3.368 \\
$\sigma_{u m}$ & 13.090 & -4.178 \\
$\sigma_{s k}$ & -6.593 & 3.838 \\
$\sigma_{u k}$ & 0.707 & 3.819 \\
$\sigma_{k m}$ & 0.801 & 4.171 \\
$\sigma_{s u}$ & 2.146 & 5.776 \\
\hline
\end{tabular}


Table 3. Time series elasticities of substitution

\begin{tabular}{lllllll}
\hline Years & $\sigma_{s u}$ & \multicolumn{1}{c}{$\sigma_{s m}$} & $\sigma_{u m}$ & $\sigma_{s k}$ & $\sigma_{u k}$ & $\sigma_{m k}$ \\
\hline 1965 & 1.7293 & 20.2312 & -12.4710 & 0.7541 & 0.7800 & 1.4137 \\
1966 & 1.7580 & 14.3067 & -7.9970 & 0.7475 & 0.7860 & 1.4028 \\
1967 & 1.7665 & 15.5366 & -8.7677 & 0.7495 & 0.7860 & 1.8376 \\
1968 & 1.7641 & 14.2734 & -7.7962 & 0.7437 & 0.7878 & 1.4076 \\
1969 & 1.7810 & 12.7761 & -6.6639 & 0.7401 & 0.7908 & 1.4041 \\
1970 & 1.7760 & 13.2313 & -6.8967 & 0.7392 & 0.7902 & 1.3993 \\
1971 & 1.7688 & 20.5027 & -11.1920 & 0.7396 & 0.7880 & 1.3832 \\
1972 & 1.7874 & 18.6200 & -9.8830 & 0.7382 & 0.7907 & 1.3802 \\
1973 & 1.7720 & 14.2630 & -7.1910 & 0.7240 & 0.7942 & 1.4797 \\
1974 & 1.7754 & 11.4713 & -5.5255 & 0.7172 & 0.7971 & 1.5488 \\
1975 & 1.7591 & 14.8807 & -7.7780 & 0.7238 & 0.7936 & 1.5500 \\
1976 & 1.7430 & 14.9886 & -7.8726 & 0.7182 & 0.7933 & 1.6399 \\
1977 & 1.7579 & 17.6532 & -9.3612 & 0.7212 & 0.7939 & 1.5737 \\
1978 & 1.7677 & 14.8684 & -7.5747 & 0.7176 & 0.7961 & 1.5856 \\
1979 & 1.7811 & 11.4671 & -5.4708 & 0.7122 & 0.7994 & 1.6147 \\
1980 & 1.7725 & 11.2548 & -5.4876 & 0.7143 & 0.7986 & 1.5600 \\
1981 & 1.7752 & 9.7838 & -4.6203 & 0.7107 & 0.8003 & 1.5330 \\
1982 & 1.7436 & 12.1652 & -6.3293 & 0.7174 & 0.7952 & 1.5783 \\
1983 & 1.7370 & 15.4255 & -8.2575 & 0.7186 & 0.7929 & 1.6869 \\
1984 & 1.7900 & 11.7792 & -5.5176 & 0.7104 & 0.8001 & 1.5765 \\
1985 & 1.8001 & 11.0502 & -4.9601 & 0.7039 & 0.8025 & 1.5958 \\
1986 & 1.8060 & 11.0390 & -4.8746 & 0.6998 & 0.8038 & 1.6179 \\
1987 & 1.8128 & 11.1887 & -4.8975 & 0.6968 & 0.8051 & 1.6386 \\
\hline
\end{tabular}

With regard to real balances, it seems to be a substitute w.r.t. non-production workers (as $\left.\sigma_{s m}>0\right)$ and a complement to production workers $\left(\sigma_{u m}<0\right)$. This latter result provides some interesting evidence for the supply-side effects of real balances. We may explain this in the following way. Suppose that the interest rates (the price of money) in the economy increase due to a restrictive monetary policy, resulting in a decreased demand for production workers (as money is a complement to $X_{u}$ ). This, in turn, may shift the aggregate supply curve upward and to the left. At the same time, due to higher interest rates it may suppress the private investment demand thereby shifting the aggregate demand curve downward to the left. Consequently, the employment and level of output may decrease even with higher prices. ${ }^{7}$

\footnotetext{
7 This macroeconomic analysis based on our results should be viewed with caution as our estimates are based on a sectoral level (manufacturing) data and on a cost minimization approach where the level of output is assumed to be fixed. Thus, in order to draw more general macroeconomic conclusions, further research is needed in this area.
} 
Another interesting result based on the elasticity of substitution is the relative high substitutability between real balances and capital $\left(\sigma_{k m}=2.146\right)$. This result seems fairly intuitive when money is considered to be a working capital.

We have also calculated the cost shares of all the factors for each year based on the estimated parameters of the cost function and they are reported in Table 4. The share of money, though small in the total cost of the Canadian manufacturing sector, has, nevertheless, increased over the years. In fact, the share of real balances has more than doubled from the mid sixties to the late eighties on a percentage point basis. The cost share of capital, on the other hand, did not change much over the years.

The time series of factor cost shares of production and non-production workers reveal some interesting and crucial aspects of the Canadian manufacturing industries. The factor shares of production workers (unskilled) over the years have steadily increased while, during the same period, the workers of the non-production (skilled) sector experienced some decline in their factor shares in the total cost. Our findings regarding cost shares of labourers and

Table 4. Factor cost shares

\begin{tabular}{|c|c|c|c|c|}
\hline Years & $S_{s}$ & $S_{u}$ & $S_{k}$ & $S_{m}$ \\
\hline 1965 & 0.2093 & 0.4298 & 0.3592 & 0.0016 \\
\hline 1966 & 0.2018 & 0.4291 & 0.3667 & 0.0023 \\
\hline 1967 & 0.2000 & 0.4280 & 0.3698 & 0.0022 \\
\hline 1968 & 0.1989 & 0.4317 & 0.3669 & 0.0024 \\
\hline 1969 & 0.1950 & 0.4309 & 0.3713 & 0.0028 \\
\hline 1970 & 0.1949 & 0.4340 & 0.3684 & 0.0027 \\
\hline 1971 & 0.1926 & 0.4431 & 0.3626 & 0.0017 \\
\hline 1972 & 0.1892 & 0.4405 & 0.3684 & 0.0019 \\
\hline 1973 & 0.1910 & 0.4448 & 0.3617 & 0.0025 \\
\hline 1974 & 0.1915 & 0.4419 & 0.3634 & 0.0032 \\
\hline 1975 & 0.1950 & 0.4434 & 0.3593 & 0.0023 \\
\hline 1976 & 0.1974 & 0.4475 & 0.3528 & 0.0023 \\
\hline 1977 & 0.1936 & 0.4473 & 0.3571 & 0.0020 \\
\hline 1978 & 0.1917 & 0.4459 & 0.3600 & 0.0024 \\
\hline 1979 & 0.1901 & 0.4421 & 0.3647 & 0.0032 \\
\hline 1980 & 0.1933 & 0.4394 & 0.3640 & 0.0032 \\
\hline 1981 & 0.1941 & 0.4362 & 0.3660 & 0.0037 \\
\hline 1982 & 0.2007 & 0.4397 & 0.3568 & 0.0028 \\
\hline 1983 & 0.1993 & 0.4467 & 0.3518 & 0.0022 \\
\hline 1984 & 0.1869 & 0.4445 & 0.3654 & 0.0031 \\
\hline 1985 & 0.1839 & 0.4458 & 0.3669 & 0.0034 \\
\hline 1986 & 0.1820 & 0.4473 & 0.3672 & 0.0035 \\
\hline 1987 & 0.1828 & 0.4479 & 0.3684 & 0.0034 \\
\hline
\end{tabular}


capital reinforce some of the similar observations made by researchers elsewhere. [e.g., See Daly and Globerman (1976), Britton and Gilmore (1978), May and Denny (1979), Danny and Fuss (1982), Helliwell (1984), Daly and Rao (1985)]. In this context Bryan (1986, pp. 105-6) writes:

Canadian manufacturing [industry] is dominated by slow-growing industries which in some areas suffer substantial competition from the newer industrialized countries. Many industries are plagued by low productivity and high labour [production or un-skilled] costs...

Another factor that contributes to low productivity is insufficient research and development expenditures [or capital].... Technological advancement goes hand in hand with a technically trained labour force and some technical sophistication on the part of management, both of which Canadian [manufacturing] industry appears to be lacking.

\section{Conclusions}

The purpose of this paper was to investigate whether or not real balances are important productive inputs of the aggregate Canadian manufacturing industries. To this end, a four input $\left(X_{k}, X_{s}, X_{u}, X_{m}\right)$ translog cost function was employed for estimating production parameters, demand and substitution elasticities using annual Canadian data over the period 1965-87.

One of the important findings of our study is that the real cash balances are indeed important factors of production for the aggregate Canadian manufacturing sector. This, of course, does not mean that the real balances are like any other factors of production but rather they indirectly help and facilitate the process of production. Our own and cross-price elasticities estimates suggest that the demand for real balances, production worker and capital are fairly inelastic and that the production workers and money appear to be complements to each other. On the other hand, money seems to be a substitute for capital and non-production workers. Another interesting result that emerges from our study is the significance of the potential supply side effect of a change in the interest rate on both labour demand and supply of output.

Finally, although the primary focus of this study was to examine the importance of money in the production function, some of our findings on historical factor cost shares based on the estimated translog cost function, however, provide interesting evidence on the cost structure of production and 
non-production workers. In particular, our results in this regard simply reinforce the assertion that one of the important reasons for the Canadian manufacturing industries to be non-competitive is the increasing cost shares of production workers over the period considered.

\section{Appendix A}

In this appendix we present the formulation of the user cost of capital $\left(P_{k}\right)$ services as used by Lodh (1984) for the Canadian aggregate manufacturing sector. The equations defining the user cost are given below:

$\left.P_{k}=(P I)[R+\delta)(1-I T C)\left(1-\tau^{e} \chi\right)\right] /(1-\tau)$, where

$R=\varepsilon^{e} R E+(1-\varepsilon)^{e} R B$

$R B=I R(1-\tau)-\varrho^{e}$

The variables are defined as:

$P I$ is the price of investment good,

$R \quad$ is the real discount rate,

$\tau \quad$ is the actual effective corporate tax rate,

$\tau^{e} \quad$ is the expected effective corporate tax rate,

$\delta \quad$ is the economic depreciation rate (based on the straight-line method applied to a life span of the capital good),

ITC is the investment tax credit rate,

$\chi$ is the discounted capital cost allowances per dollar of investment,

$\varepsilon \quad$ is the actual equity share in total capital,

$\varepsilon^{e} \quad$ is the expected equity share in total capital,

$R E$ is the real equity cost of capital with inflation adjusted,

$R B$ is the real industrial bond rate (after tax) with inflation adjusted,

$I R$ is the industrial bond rate (McLeod, Young and Weir),

$\varrho^{e} \quad$ is the expected inflation rate.

The above equations for the user cost of capital have been formulated from the standard Hall and Jorgenson type of model to suit the Canadian context given the data on appropriate variables. The cost of debt capital follows the Feldstein approach that adjusts for inflation expectation in the overall economy and the effective tax rate of the industry. Inflation expectations are, however, based on expected inflation rate of CPI rather than industry-specific inflation rate since the latter has been traditionally difficult to postulate on 
theoretical grounds. The discounted capital cost allowance per dollar of investment was calculated on the assumption that the following variables are known:

a) tax depreciation rate,

b) the expected life span of the capital good, and

c) the knowledge of the depreciation formula to be applied to a particular capital good purchased.

[For a detailed discussion on the appropriateness and shortcomings of different variables in the equation, the reader should refer to Lodh (1984).]

\section{Appendix B}

In this appendix, we provide a brief discussion on the estimation procedure adopted in the study. Following conventional practice, we specify additive disturbances for the cost function (3) and each of the share equations in (4). We also assume that these disturbances have a joint normal distribution and allow for contemporaneous correlation across equations. Furthermore, the cost shares (by definition) in (4), and the right hand sides of these cost share equations must also add to unity. Hence, the errors in the share equations must add to zero for each observation. This implies that one of the share equations must be dropped as their covariance structure is not of full rank [e.g., Barten (1969)].

Following Zellner (1962), the system can be estimated using the seemingly unrelated regression technique, and the estimates so obtained are invariant to the choice of the equation to be dropped. It has been shown that a maximum likelihood estimate of the share equations guarantees such invariance. Dhrymes (1970) has shown that continuing iteration of Zellner's method, until the covariance matrix converges, yields the maximum likelihood estimates. This method is computationally equivalent to maximum likelihood and ensures invariance of parameter estimates to the choice of the share equation dropped.

Since there are four cost share equations in our model, we used the property of the invariance to check our estimtes by using the linear homogeneity conditions in Equation (4). For example, solving the homogeneity conditions for the parameters of the capital equation $\left(\alpha_{k}, \gamma_{k k}, \gamma_{k s}, \gamma_{k u}, \gamma_{k m}, \gamma_{q k}\right)$ and substituting them into the cost function gives the following set of equations: 


$$
\begin{aligned}
& \ln (C)= \alpha_{0}+\alpha_{q} \ln Q+(1 / 2) \alpha_{q q}(\ln Q)^{2}+\alpha_{s} \ln \left(P_{s} / P_{k}\right)+\alpha_{u} \ln \left(P_{u} / P_{k}\right) \\
&\left.+\alpha+\ln \left(P_{k}\right)+(1 / 2) \cdot \gamma_{s s} \ln \left(P_{s} / P_{k}\right)\right\}^{2}+(1 / 2) \cdot \gamma_{u u}\left\{\ln \left(P_{u} / P_{k}\right)\right\}^{2} \\
&\left.+(1 / 2) \cdot \gamma_{m m} \ln \left(P_{m} / P_{k}\right)\right\}^{2}+\gamma_{s u} \ln \left(P_{s} / P_{k}\right) \ln \left(P_{u} / P_{k}\right) \\
&+\gamma_{s m} \ln \left(P_{s} / P_{k}\right) \ln \left(P_{m} / P_{k}\right)+\gamma_{u m} \ln \left(P_{u} / P_{k}\right) \ln \left(P_{m} / P_{k}\right) \\
&+\gamma_{q s} \ln Q \ln \left(P_{s} / P_{k}\right)+\gamma_{q u} \ln Q \ln \left(P_{u} / P_{k}\right) \\
& \quad+\gamma_{q m} \ln Q \cdot \ln \left(P_{m} / P_{k}\right)+\mu_{c} ; \\
& S_{s}=\left\{\left(P_{s} X_{s}\right) /\left(P_{s} X_{s}+P_{u} X_{u}+P_{m} X_{m}+P_{k} X_{k}\right)\right\} \\
&=\alpha_{s}+\alpha_{s s} \ln \left(P_{s} / P_{k}\right)+\gamma_{s u} \ln \left(P_{u} / P_{k}\right)+\gamma_{s m} \ln \left(P_{m} / P_{k}\right)+\gamma_{q l} \ln Q+\mu_{s} ; \\
& S_{u}=\left\{\left(P_{u} X_{u}\right) /\left(P_{s} X_{s}+P_{u} X_{u}+P_{m} X_{m}+P_{k} X_{k}\right)\right\} \\
&=\alpha_{u}+\gamma_{s u} \ln \left(P_{s} / P_{k}\right)+\gamma_{u u} \ln \left(P_{u} / P_{k}\right)+\gamma_{u m} \ln \left(P_{m} / P_{k}\right)+\gamma_{q u} \ln Q+\mu_{u} ; \\
& S_{m}=\left\{\left(P_{m} X_{m}\right) /\left(P_{s} X_{s}+P_{u} X_{u}+P_{m} X_{m}+P_{k} X_{k}\right)\right\} \\
&=\alpha_{m}+\gamma_{s m} \ln \left(P_{s} / P_{k}\right)+\gamma_{u m} \ln \left(P_{u} / P_{k}\right)+\gamma_{m m} \ln \left(P_{m} / P_{k}\right)+\gamma_{q m} \ln Q+\mu_{m} ;
\end{aligned}
$$

where $\mu_{c}, \mu_{s}, \mu_{u}$ and $\mu_{m}$ are the additive disturbances in the cost, production labour share, non-production worker share and money share equations, respectively. There are six parameters which do not appear in the above equations, namely, $\alpha_{k}, \gamma_{k k}, \gamma_{k s}, \gamma_{k u}, \gamma_{k m}$ and $\gamma_{q k}$. However, these are linear combinations of the consistent and asymptotically efficient estimates of other known parameters which are determined residually using the constraint imposed on the share equations.

\section{References}

Barten A (1969) Maximum Likelihood Estimation of a Complete System of Demand Equations. European Economic Review 1:7-73

Berndt E, Christensen L (1973) The Internal Structure of Functional Relationships: Separability, Substitution, and Aggregation. Review of Economic Studies 40:403-410 Berndt E, Wood D (1975) Technology, Prices, and Derived Demand for Energy. Review of Economics and Statistics 57:259-268 
Binswanger H (1974) A Cost Function Approach to the Measurement of Elasticities of Factor Demand and Elasticities of Substitution. American Journal of Agricultural Economics 56:377-386

Britton J, Gilmore N (1978) The Weakest Link, A Technological Perspective on Canadian Industrial Underdevelopment, Background Study No 43. Science Council of Canada, Ottawa: Supply and Services

Bryan I (1986) Economic Policies in Canada. Butterworths, Second Edn

Caves D, Christensen L (1980) Global Properties of Flexible Functional Forms. American Economic Review 70:422-432

Christensen L, Greene W (1976) Economies of Scale in US Electric Power Generation. Journal of Political Economy 84:655-676

Christensen, L, Jorgenson D, Lau J (1973) Transcendental Logarithmic Production Frontiers. Review of Economics and Statistics 55:28-45

Daly D, Globerman S (1976) Tariff and Science Policies: Applications of a model of Nationalism. Toronto: Ontario Economic Council

Daly M, Rao P (1985) Some Myths and Realities Concerning Canada's Recent Productivity Slowdown and Their Policy Implications. Canadian Public Policy 9:206-218

Dennis E, Smith K (1978) A Neoclassical Analysis of the Demand for Real Cash Balances by Firms. Journal of Political Economy 86:793-813

Denny N, Fuss M (1982) Productivity: A Selective Survey of Recent Developments and the Canadian Experience. Toronto: Ontario Economic Council

Friedman M (1969) The Optimum Quantity of Money, and other Essays. Chicago: Aldine Harkness J (1984) Optimal Exchange Intervention for a Small Open Economy. In: Bhandari J, Turnovsky S (eds) Exchange Rate Management Under Uncertainty, Cambridge, Mass

Helliwell J (1984) Stagflation and Productivity Decline in Canada, 1974-82. Canadian Journal of Economics 27:191-217

Jansen D (1985) Real Balances in an Ad Hoc Keynesian Model and Policy Ineffectiveness. Journal of Money, Credit and Banking, 17:378-386

Lodh B (1984) Disaggregated Investment Function of Canadian Non-Residential Business Sector: Candide Model 3.0. Mimeograph, Economic Council of Canada

Lucas R, Rapping L (1969) Real Wages, Employment, and Inflation. Journal of Political Economy 77:721-754

May D, Denny M (1979) Post-War Productivity Increase in Manufacturing. Canadian Journal of Economics 12:29-42

Sephton P (1986) Money in the Canadian Production Function Revisited. ACEA Conference Paper

Shephard R (1970) Theory of Cost and Production Functions. Princeton University Press

Sinai A, Stokes H (1972) Real Money Balances: An Omitted Variable from the Production Function. Review of Economics and Statistics 54:290-296

Uzawa H (1962) Production Functions with Constant Elasticities of Substitution. Review of Economic Studies 29:291-299

You J (1981) Money, Technology, and the Production Function: An Empirical Study. Canadian Journal of Economics 14:515-524 